\title{
Strangulated inguinal hernia of the bladder and intestinal necrosis
}

Serhat Doğan ${ }^{1}$, Mehmet Erikoglu²

${ }^{1}$ Department of General Surgery, Malatya Education and Research Hospital, Malatya, Turkey

${ }^{2}$ Department of Surgery, Faculty of Medicine, Necmettin Erbakan University, Konya, Turkey

Submitted: 11 March 2017

Accepted: 3 April 2017

Arch Med Sci Civil Dis 2017; 2: e87-e88

DOI: https://doi.org/10.5114/amscd.2017.67219

Copyright $\odot 2017$ Termedia \& Banach

Inguinal hernia is a common problem. Occasionally surgeons are surprised with unconventional structures [1]. The most frequently incarcerated organs are the small intestines, omentum and colon [2]. Adhesions and bands that form in the inguinal hernia can cause strangulation and intestinal perforation [3]. In the inguinal hernia sac the bladder is very rare [4]. In this case of strangulated inguinal hernia operation, we found necrotic bowel and bladder in the hernia sac. An 80-year-old male patient had a mass in the right groin with swelling, abdominal pain, nausea and vomiting, and inability to defecate, and so he came to the emergency department with these complaints.

On examination, the right inguinal skin rash, edema, and a painful palpable mass measuring about $6 \times 8 \mathrm{~cm}$ was detected. Abdominal distension, rebound and defense were positive. Normal leukocytes in laboratory tests, urea: $180 \mathrm{mg} / \mathrm{dl}$, creatine: $2.62 \mathrm{mg} / \mathrm{dl}$, C-reactive protein (CRP): $199.92 \mathrm{mg} / \mathrm{l}$ were measured. Directly abdominal radiography showed the air-fluid level in the small intestine (Figure 1). The patient was diagnosed with strangulated inguinal hernia and operated on.

In the operation the small bowel was necrotic and perforation was detected at $20 \mathrm{~cm}$ in multiple segments of the small bowel in the hernia sac. The bladder was also found to be necrotic. Because of the dirty and infected abdomen, the necrotic small bowel was resected and double barrel ileostomy was performed. We irrigated the abdomen with plenty of saline. Partial cystectomy of the bladder was performed. In the postoperative period the intubated patient was taken to the intensive care unit. On the first postoperative day the patient died because of cardiac arrest and multiorgan failure.

The bladder and small bowel with both of them necrotic have not been reported in the literature. As a result, in cases of strangulated inguinal hernia in elderly patients who are operated on for strangulated hernia we should also keep in mind the bladder.

\section{Conflict of interest}

The authors declare no conflict of interest.

\author{
Corresponding author: \\ Serhat Doğan \\ Department of \\ General Surgery \\ Malatya Education \\ and Research \\ Hospital \\ 44000 Malatya, Turkey \\ Phone: +90 5069306797 \\ E-mail:drserhatdogan@ \\ gmail.com
}




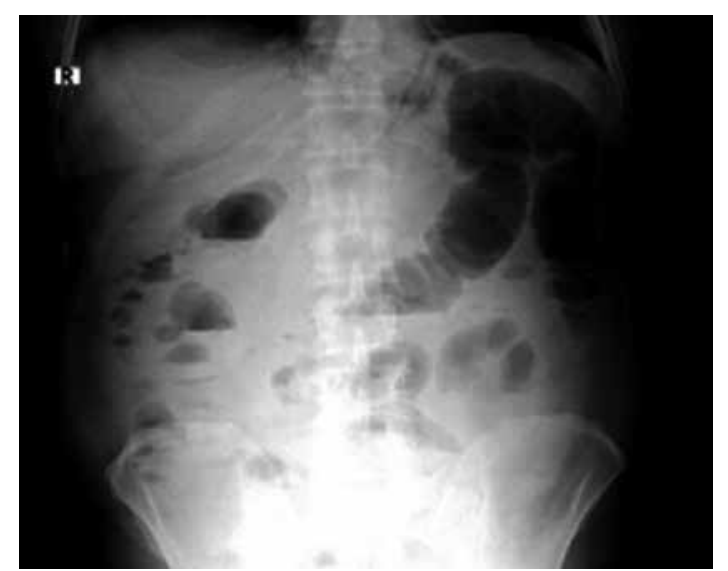

Figure 1. Direct abdominal radiography showed the air-fluid level in the small intestine

\section{References}

1. Gallegos NC, Dawson J, Jarvis M, Hobsley M. Risk of strangulation in groin hernias. Br J Surg 1991; 78: 1171-3.

2. Tufnell ML, Abraham-Igwe C. A perforated diverticulum of the sigmoid colon found within a strangulated inguinal hernia. Hernia 2008; 12: 421-3.

3. Çakır M, Gündeş E. Inguinal hernia due to a band adhesion within the hernial sac. Med I Selçuk 2016; 32: 33-4.

4. Fuerxer F, Brunner P, Cucchi JM, Mourou MY, Bruneton JN. Inguinal herniation of a bladder diverticulum. Clin Imaging 2006; 30: 354-6. 